\title{
INSERCIÓN LABORAL DE MUJERES EN IQUIQUE DURANTE EL CICLO DEL SALITRE: DIVISIÓN SEXUAL DEL TRABAJO Y RELACIONES SOCIALES DE GÉNERO (1890-1920)*
}

\author{
EMPLOYMENT OF WOMEN IN IQUIQUE DURING THE NITRATE CYCLE: \\ SEXUAL DIVISION OF LABOUR AND GENDER-BASED SOCIAL RELATIONS \\ (1890-1920).
}

Karelia Cerda Castro $^{* * *}$ y Constanza Rojas Contreras ${ }^{* * *}$

\begin{abstract}
Este artículo presenta un análisis del proceso de inserción laboral de mujeres en Iquique durante el Ciclo de Expansión del Salitre. La historiografía nacional ha dado cuenta de este fenómeno de forma generalizada y homogénea para los principales centros industriales del país (Iquique, Valparaíso, Santiago y Concepción) sin atender a las particularidades regionales; por tanto, el objetivo de esta investigación es analizar las características locales, tanto en sus aspectos cualitativos como cuantitativos, a partir de un examen de las principales fuentes estadísticas y documentales disponibles. Como hipótesis, se plantea que las condiciones en que se produjo la inserción laboral de mujeres en el contexto se perfilaron a partir de las categorías de género asociadas a lo femenino en tensión con las necesidades de mano de obra de la economía salitrera, generando así discursos y prácticas en torno a la figura de la mujer trabajadora.
\end{abstract}

Palabras claves: ciclo del salitre, trabajo, género, mujeres obreras.

This article presents an analysis of the process of employment of women in Iquique during the Saltpeter Expansion Cycle. The national historiography has accounted for this phenomenon in a generalized and homogeneous way for the industrial centers of the country (mainly Iquique, Valparaíso, Santiago and Concepción) without attending to its regional specificities. Therefore, the objective of this research was to analyze the local characteristics in both its qualitative and quantitative aspects, through an review of the main available statistical and documentary sources. As a hypothesis, it is suggested that the conditions in which women were inserted into the labor market in the context were outlined from the gender categories associated with the feminine in tension with the needs of the saltpeter economy, thus generating discourses and practices around the figure of working women.

Key words: Cycle of the saltpeter, work, gender, working women.

\section{Introducción}

El ciclo del salitre se inició en Tarapacá bajo administración del Estado peruano. Según señala Sergio González, la industria salitrera se desarrolló a partir de la década de 1830 y cobraría especial protagonismo en términos de aporte a las arcas fiscales peruanas en 1872, año en que iguala -para luego desplazar-al guano como principal producto de exportación (González, 2014). Tras la Guerra del Pacífico y la ocupación chilena del territorio, el salitre se convirtió en uno de los principales pilares de la economía nacional, lo que permitió la consolidación del Estado oligárquico y la república parlamentaria, además de la construcción de importantes obras públicas y modernización de la infraestructura del país. No obstante su competitividad en los mercados mundiales decayó durante el complejo escenario económico y político de la Primera Guerra Mundial, registrándose su inflexión final en 1919, a partir de ello su comercialización descendió progresivamente hasta la crisis de 1930 (González, 2014). Es en este contexto en que se produjo una creciente inserción de mano de obra femenina en el trabajo asalariado extradoméstico, en distintas áreas en proceso de desarrollo.

Bajo el modelo primario exportador basado en la explotación y comercialización del salitre,

\footnotetext{
* $\quad$ Esta investigación se desarrolló en el marco del proyecto Fondecyt Regular código n ${ }^{\circ} 1171198$ titulado "La sociedad salitrera en clave heterotópica: Importancia urbana del cantón como refutador de la hipótesis del enclave en el Norte Grande, 18781930", a cargo de Pablo Artaza B. y Sergio González M.

** Departamento de Ciencias Históricas y Geográficas, Universidad de Tarapacá. Arica, Chile. Correo electrónico: kcerdac@academicos.uta.cl

*** Departamento de Ciencias Históricas y Geográficas, Universidad de Tarapacá. Arica, Chile. Correo electrónico: constanzamrojas@ gmail.com
} 
la región de Tarapacá atrajo a miles de hombres y mujeres provenientes del sur de Chile y otros países para ocuparse en las alternativas que ofrecían tanto la pampa como los puertos de embarque de salitre. Lo anterior impactó en la rápida expansión de la ciudad de Iquique, cuyos límites se ampliaron en condiciones precarias, en contraste con la bonanza económica, las condiciones de vida de la clase trabajadora se pauperizaron, quedando en evidencia la precariedad de las habitaciones obreras, los bajos salarios y la ausencia de leyes sociales que garantizaran el bienestar de las familias trabajadoras.

Durante el ciclo de expansión del salitre se conjugaron múltiples factores económicos, políticos y sociales que permitieron la dinamización de distintos sectores productivos. Así, el área de servicios experimentó una gran diversificación, principalmente gracias al desarrollo urbano, a la vez que permitió absorber a parte importante de la mano de obra concentrada en las ciudades, masificándose los establecimientos comerciales, almacenes, bodegas, agencias aduaneras, entidades financieras, servicios hoteleros y restaurantes, servicios domésticos, entre otros. Respecto de la actividad industrial, señalan Julio Pinto y Luis Ortega que en Chile se inició un proceso de industrialización en el último tercio del siglo XIX estrechamente vinculado con la exportación de materias primas, lo que aumentó la necesidad de bienes de capital, equipos y maquinarias (Pinto y Ortega, 1990); asimismo, es posible destacar el rol que jugaron el incremento de la conectividad ferroviaria y las actividades portuarias en el fomento de la circulación de bienes, servicios y personas, favoreciendo además la concentración de población en centros urbanos y pueblos mineros que acrecentó la demanda de productos básicos de consumo, potenciando así la producción manufacturera de vestuario, textiles, alimentos procesados y otros insumos.

Hacia fines del siglo XIX, Tarapacá era una de las provincias con mayor densidad de población urbana del país, mientras que la ciudad de Iquique duplicó su población en el decenio de 1885 a 1895. Según los Censos de Población de 1895, 1907 y 1920, la población femenina representó entre el $45 \%$ y $48 \%$ del total de habitantes de las zonas urbanas, existiendo una mayor permanencia de las mujeres en las ciudades en relación con los varones, según Elizabeth Hutchison esto se explica por la existencia de diferentes formas de migración campo-ciudad relacionadas con las oportunidades laborales basadas en el género, señala que el trabajo de los varones fue de carácter estacional y diverso en faenas mineras, portuarias y en la industria ferrocarrilera, mientras que las mujeres encontraron mayores oportunidades en las ciudades (Hutchison 2006).

Las fuentes laborales disponibles para las mujeres estuvieron definidas en razón de las representaciones sociales del género, determinando así la concentración de la mano de obra en actividades consideradas apropiadas moral y físicamente, produciéndose la feminización de ciertas ocupaciones; hacia finales del siglo XIX y las primeras décadas del siglo XX se amplió el acceso al trabajo asalariado extradoméstico, es así que las pequeñas labores de costura e hilandería, lavandería, preparación y venta de alimentos, entre otras, dieron paso al empleo en espacios como fábricas, talleres y establecimientos de distintos servicios. El proceso de inserción laboral de las mujeres estuvo mediado por diversos factores económicos, políticos y sociales en donde el género operó como un elemento constitutivo de las dinámicas y características de este fenómeno.

\section{Inserción laboral de mujeres en Chile: características generales}

Las mujeres de los sectores populares han sido representadas bajo patrones de género tradicionales, tanto en el plano práctico como en el simbólico en relación con estereotipos de género (tríada madre/ esposa/dueña de casa) y solo de forma secundaria como trabajadoras remuneradas, especialmente cuando su trabajo ha adquirido mayor visibilidad. No obstante, a lo largo de décadas desarrollaron diversas actividades para generar ingresos, las que se realizaban principalmente al interior del propio hogar o en un hogar ajeno -como cocineras y empleadas domésticas- y en algunos espacios externos, dichas actividades eran además compatibles con labores domésticas y cuidado de los hijos. La ocupación chilena de Tarapacá coincidió con los cambios de las condiciones laborales que experimentaron las mujeres al ampliarse su ingreso al mercado laboral extradoméstico, las últimas décadas del siglo XIX fueron escenario de transformaciones en la estructura productiva del país que incidieron en el aumento de la demanda de mano de obra barata y posibilitaron la paulatina masificación del trabajo asalariado femenino e infantil en establecimientos: 
"Hacia 1880, fábricas de vestuario y confección, las industrias procesadoras de alimentos y de tabaco, las textiles, las casas comerciales, los servicios urbanos, las agencias financieras y oficinas estatales, se transformaron en los espacios cotidianos de acción de los sectores femeninos medios y de bajos ingresos, a través de los cuales se definió la experiencia de la modernización" (Veneros y Ortega, 2011:153).

A nivel nacional, la incorporación de las mujeres al mercado laboral formal y bajo relaciones de producción modernas fue gradual, señala Alejandra Brito que una de las consecuencias de la constante transformación de las zonas urbanas para las mujeres sería el traslado de su espacio cotidiano desde los antiguos ranchos hacia los conventillos, en dicho contexto persistieron las formas de trabajo arcaicas y marginales del siglo XIX hasta al menos la década de 1920: "Del total de mujeres trabajadoras, en promedio 76,2 por ciento se dedicó a estas actividades; esto es, dos tercios de la población trabajadora femenina eran mujeres pobres que realizaban actividades marginales muy alejadas de lo que es una fuerza de trabajo moderna" (Brito, 1995:40-41), por tanto, fue un segmento reducido el que llegó a proletarizarse en una primera instancia. De forma similar, indica Joan W. Scott que para el caso de las ciudades industriales o en su primera fase de industrialización en Europa, las áreas tradicionales -e informales- de la economía concentraron mayor cantidad de mano de obra femenina que la industria (Scott 2006). Se establece así que el proceso de inserción laboral femenino no estuvo vinculado únicamente al sector fabril sino que con múltiples actividades formales e informales, especialmente aquellas que requerían de menor especialización.

Resulta complejo establecer la cantidad exacta de mujeres que trabajaban asalariadas tanto a nivel nacional como en Iquique durante este periodo por diversos motivos. En primer lugar, los registros censales son imprecisos, según señala Hutchison los cambios metodológicos y la modernización de este instrumento derivó en la tergiversación de la información recabada acerca del trabajo femenino (Hutchison 2000), a partir del censo de 1907 la mano de obra femenina -menormente calificadadecreció numéricamente en el registro, aumentando a su vez la cantidad de mujeres dedicadas a "otras profesiones" sin especificar (Hutchison 2006). En segundo lugar, el registro del oficio de cada trabajador dependía del criterio de los encuestadores, quienes, según Thelma Gálvez y Rosa Bravo, clasificaban la ocupación en relación con la cantidad de horas, frecuencia con que se realizaba o la cantidad de ingresos que generaba, lo que eclipsa el hecho de que muchas mujeres ejercían más de una labor remunerada (Gálvez y Bravo 1992).

Todo lo anterior dificulta analizar cuantitativamente el trabajo femenino. Entre los problemas metodológicos que se derivan de la confiabilidad de las estadísticas, podemos mencionar que el trabajo en el propio domicilio tendió a confundirse con las labores domésticas. Hutchison enfatiza el ejemplo de las trabajadoras textiles, quienes habitualmente trabajaban desde sus hogares o llevaban parte de la producción de los talleres al domicilio, lo que fue considerado como "quehaceres domésticos" y, por tanto, estas trabajadoras figuraron como sujetos económicamente inactivos (Hutchison 2006); de igual forma sucedió con actividades como la preparación y venta de alimentos, bebidas y otras manufacturas menores. Otra modalidad de actividad informal que fue propensa a quedar fuera de los registros - por su ocupación esporádica y de tiempo parcial-, era el trabajo realizado a domicilio de los clientes, señala Mercedes Tatjer para el caso de Barcelona a principios del siglo XX, que las mujeres desempeñaban tareas remuneradas en hogares ajenos como la venta de productos y utensilios, labores de costura y confección, limpieza, cocina, lavado, etc., que les permitían compatibilizar el trabajo con sus propias labores domésticas y cuidado de familiares dependientes -hijos, ancianos, enfermos- (Tatjer 2002).

Como se mencionó anteriormente, la complementación de dos o más actividades remuneradas no fue considerada en las estadísticas, es posible destacar que la movilidad entre oficios fue una constante entre la población femenina en razón de los bajos índices de especialización, la precariedad laboral y la necesidad de compatibilizar las labores domésticas. Además, la dedicación de forma permanente o esporádica a la prostitución, posibilitó que muchas mujeres declarasen otro tipo de oficios "inflando las declaraciones en ciertas ocupaciones como en los servicios de lavado y costura" (Hutchison 2006). Finalmente, tanto los censos de población como los Anuarios Estadísticos son instrumentos mediados por las construcciones simbólicas de su contexto de producción, por tanto la categoría de trabajo se presenta en relación con estereotipos y 
roles de género, lo que permitía legitimar al hombre como sujeto trabajador por excelencia y, por tanto, al trabajo como una actividad masculina, constituyendo una dimensión de la que la mujer participa de forma esporádica, secundaria y accidental, cuyos ingresos y los mecanismos para su obtención fueron considerados como complementarios para las unidades domésticas lideradas por un jefe de hogar varón.

El escenario figurado de una familia tradicional compuesta por un jefe de hogar, esposa e hijos no siempre fue una realidad entre los sectores populares, por el contrario, situaciones como el abandono del hogar, el alcoholismo y la violencia por parte de padres o esposos eran comunes, a este respecto señala Alejandra Brito que la identidad masculina se configuró en torno a la resistencia peonal al "arranchamiento" y a la constitución de vínculos permanentes mediante la movilidad dentro y fuera del territorio nacional (Brito, 2014). Lo anterior explica que muchas mujeres se vieran enfrentadas a liderar sus hogares y generar el sustento para sus familias, hecho que según Elizabeth Hutchison fue obviado intencionalmente por los encuestadores de los Anuarios Estadísticos en relación con los ingresos familiares, focalizándose en hogares compuestos por familias nucleares tradicionales (Hutchison 2006). Ante estas dificultades metodológicas, es necesario analizar los datos estadísticos de forma crítica, teniendo presente sus omisiones y falencias.

A nivel nacional, la cantidad y la visibilidad de trabajadoras aumentó progresivamente, pasando de 338.986 en 1895 a 509.864 mujeres con un oficio o "profesión" en 1920, registrando una mayor alza entre las dos primeras décadas del siglo XX. Es admisible destacar que hacia 1920, la fuerza laboral femenina estaba compuesta, además, por un importante contingente de trabajadoras sin oficio determinado, representado por 1.378.108 mujeres que se ganaban la vida en empleos sin especialización, regularidad en el tiempo ni mayor formalidad. Al analizar los datos censales, se puede establecer que existió una tendencia a la concentración de la mano de obra femenina en determinadas actividades industriales, en el comercio y en los servicios, siendo poco significativa su participación en otras áreas como los transportes, la administración y fuerza pública, profesiones liberales, etc. Los oficios industriales lideraron las estadísticas, especialmente en el área de los textiles -bordadoras, hilanderas, costureras, modistas, sombrereras, tejedoras y sastres-, marcando un peak de $54,5 \%$ del total de la masa de trabajadoras en 1907 (Galvez y Bravo, 1992). El alto grado de feminización de la industria textil y de vestuario, en donde las costureras y modistas fueron las más numerosas, concentró la mayor cantidad de mano de obra femenina en el país en este periodo. Esto se vincula, principalmente, con el hecho de que las mujeres desde su infancia eran socializadas en labores domésticas, dentro de estas, la costura y el bordado eran centrales, desarrollando habilidades manuales específicas que fueron aprovechadas por el mercado laboral de las manufacturas. Según Veneros y Ortega, basándose en Anuarios Estadísticos entre 1911 y 1926, fueron solo 7 los sectores industriales que concentraron al $90,8 \%$ de la mano de obra femenina fabril: vestuario $(40,7 \%)$, alimentos $(11,6 \%)$, textiles $(11,4 \%)$, cueros y pieles $(11,1 \%)$, tabaco $(7,5 \%)$, químicos $(5,6 \%)$ y bebidas $(2,9 \%)$ (Veneros y Ortega, 2011).

En cuanto a los servicios, las mujeres se concentraron en el servicio doméstico, se destaca la gran cantidad de cocineras, sirvientas y nodrizas, figurando un peak de 40,2\% del total de la población femenina en el censo de 1895 (Gálvez y Bravo, 1992). Al respecto, Amalia Mauro, Lorena Godoy y Ximena Díaz señalan que la mayor parte de dichos empleos fue ocupado por mujeres, principalmente tareas relacionadas al cuidado, como preparación de alimentos y bebidas, amamantamiento y cuidado de niños, hospedería, entre otras (Mauro et al. 2009). La lavandería ocupó el mayor porcentaje nacional de mujeres del rubro de servicios, con un promedio del $39,7 \%$ a lo largo del periodo. En las ocupaciones de sirvientes y cocineros los hombres solo representaban al $22 \%$ del servicio doméstico mientras que las mujeres un promedio de $78 \%$, destacando por lo demás que el oficio de nodrizas -por cuestiones biológicas- era ocupado únicamente por mujeres. En general, la participación de mujeres en el área de servicios se duplicó dentro del periodo, pasando de $14,8 \%$ en 1985 a 28,5\% en $1920^{1}$. Finalmente, destacar que si bien el comercio tuvo mayor proporción de trabajadores varones, las mujeres alcanzaron un promedio de $16,6 \%$ del total del rubro en el periodo.

La constante feminización de ciertas actividades responde a patrones y roles de género, es decir, que la inserción laboral se produjo a base de la división sexual del trabajo estableciendo una correspondencia de las actividades remuneradas con las categorías de masculinidad y feminidad, de este modo las mujeres se ocuparon de actividades que generalmente eran una extensión de sus quehaceres y saberes en el 
Figura 1. Principales actividades con alta participación femenina.

\begin{tabular}{|c|c|c|c|c|c|c|}
\hline & \multicolumn{2}{|c|}{1895} & \multicolumn{2}{|c|}{1907} & \multicolumn{2}{|c|}{1920} \\
\hline & Mujeres & Hombres & Mujeres & Hombres & Mujeres & Hombres \\
\hline $\begin{array}{l}\text { Industria textil y vestuario (bordadoras, hilanderas, } \\
\text { tejedoras, costureras, modistas, sastres, sombrereras, } \\
\text { zapateros y aparadoras) }\end{array}$ & 151.314 & 20.733 & 133.644 & 26.182 & 96.900 & 23.294 \\
\hline $\begin{array}{l}\text { Área de Servicios: servicio doméstico } \\
\text { (criados, cocineros, nodrizas) y lavandería }\end{array}$ & 131.472 & 20.165 & 130.659 & 19.018 & 147.690 & 30.607 \\
\hline $\begin{array}{l}\text { Comercio (comercio establecido, } \\
\text { comercio ambulante, hotelería) }\end{array}$ & 9.614 & 44.569 & 13.146 & 67.172 & 22.629 & 119.012 \\
\hline Matronas o parteros & 814 & 0 & 1.079 & 0 & 1.643 & 3 \\
\hline $\begin{array}{l}\text { Educación (profesores, preceptores, } \\
\text { profesores de música, canto y baile) }\end{array}$ & 2.698 & 1.457 & 3.980 & 2.967 & 8.078 & 4.348 \\
\hline
\end{tabular}

Fuentes: Censos 1895,1907 y 1920.

plano doméstico, trasladándolas a nuevos espacios como talleres y fábricas, en ocaciones sin abandonar el hogar como espacio productivo.

\section{Trabajo femenino en Tarapacá urbano: aproximación estadística}

En Tarapacá, la tendencia de la inserción laboral de mujeres fue similar al escenario nacional, salvo algunas variaciones. El aumento de mano de obra femenina fue progresivo, así el censo de 1895 registró a 8.552 mujeres con profesión u oficio $(19,4 \%$ de la fuerza laboral), para 1907 declararon 12.547 mujeres (20,5\% de la fuerza laboral) y para 1920 esta cifra se duplicó contando en la provincia 43.615 mujeres declarantes $(43,4 \% \text { de la fuerza laboral })^{2}$. La ciudad de Iquique, en su estatus de puerto mayor, experimentó un crecimiento demográfico e infraestructural que posibilitó la concentración mayoritaria de trabajadoras en el trabajo extradoméstico de la provincia de Tarapacá.

Para el caso tarapaqueño, la mayor cantidad de mano de obra femenina se concentró en los servicios domésticos y la lavandería, en actividades industriales textiles y de vestuario, en tanto en el área del comercio se aprecia una menor proporción de mujeres que en a nivel general en Chile, no obstante según Alberto Prado, en la Guía General de Chile de 1904-1905, había en la ciudad de Iquique distintos establecimientos comerciales y hoteleros cuyas propietarias eran mujeres: 20 tiendas de abarrotes, 2 baratillos, 63 cafeés y fondas, 3 cantinas, 6 carnicerías, 7 hoteles, 35 distribuidoras de menestras y 1 depósito de vinos
(Prado 1905). En cuanto a profesiones de mayor especialización como la educación o profesiones liberales, la incorporación de mujeres fue más lenta que en otras partes del país, resulta interesante destacar la presencia de mujeres en oficios relacionados con el rubro de Transportes y Comunicaciones, la que si bien fue minoritaria revela su incipiente inserción en áreas altamente masculinizadas; en ese sentido, se destaca la progresiva incorporación femenina en labores de telefonistas y telegrafistas, pasando de solo 5 en 1895 a 47 en 1920, y como conductoras del ferrocarril y coches urbanos: el censo de 1895 registra 4 conductoras mientras que para 1920 solamente 2, según Allen Morrison los primeros tranvías en Chile por lo general fueron conducidos por mujeres desde la Guerra del Pacífico hasta la década de 1930 (Morrison, 2008), en la siguiente postal de Calle Baquedano -Iquique- se lee al pie como dato anecdótico que en Chile es costumbre que las mujeres conduzcan estos vehículos.

Como se ha señalado anteriormente, gran parte del empleo femenino en este contexto mantuvo características tradicionales heredadas del siglo anterior, las que incluso podrían rastrearse hasta la época colonial, lo que no solo tiene que ver con el nivel de mecanización de la producción sino también con la modernización de los sistemas de administración. Comprenderemos, por tanto, a la empresa moderna según la definición aportada por Dina Escobar, quien señala que

\footnotetext{
"Conceptualmente, la moderna empresa es concebida en este estudio, no solo como
} 
Figura 2. Principales actividades con alta participación femenina en Tarapacá (departamentos de Pisagua y Tarapacá) Censos.

\begin{tabular}{|c|c|c|c|c|c|c|}
\hline & \multicolumn{2}{|c|}{1895} & \multicolumn{2}{|c|}{1907} & \multicolumn{2}{|c|}{1920} \\
\hline & Mujeres & Hombres & Mujeres & Hombres & Mujeres & Hombres \\
\hline \multirow{2}{*}{$\begin{array}{l}\text { Industria textil y vestuario (bordadoras, hilanderas, } \\
\text { tejedoras, costureras, modistas, sastres, sombrereras, } \\
\text { zapateros y aparadoras) }\end{array}$} & 2.593 & 759 & 4.777 & 723 & 1.977 & 347 \\
\hline & $77,36 \%$ & $22,64 \%$ & $86,85 \%$ & $13,15 \%$ & $80,06 \%$ & $19,94 \%$ \\
\hline \multirow{2}{*}{$\begin{array}{l}\text { Área de servicios: servicio doméstico } \\
\text { (criados, cocineros, nodrizas) y lavandería }\end{array}$} & 4.379 & 1.008 & 4.924 & 708 & 3.022 & 860 \\
\hline & $81,28 \%$ & $18,72 \%$ & $87,42 \%$ & $12,58 \%$ & $77,84 \%$ & $22,16 \%$ \\
\hline \multirow{2}{*}{$\begin{array}{l}\text { Comercio (comercio establecido, comercio } \\
\text { ambulante, hotelería) }\end{array}$} & 837 & 3.160 & 494 & 3.244 & 542 & 5.213 \\
\hline & $20,94 \%$ & $79,06 \%$ & $13,21 \%$ & $86,79 \%$ & $9,41 \%$ & $90,59 \%$ \\
\hline \multirow{2}{*}{ Matronas y parteras } & 24 & 0 & 50 & 0 & 16 & 0 \\
\hline & $100 \%$ & $0 \%$ & $100 \%$ & $0 \%$ & $100 \%$ & $0 \%$ \\
\hline \multirow{2}{*}{$\begin{array}{l}\text { Educación (profesores, preceptores, } \\
\text { profesores de música, canto y baile) }\end{array}$} & 39 & 55 & 56 & 202 & 84 & 177 \\
\hline & $41,48 \%$ & $58,52 \%$ & $21,70 \%$ & $78,30 \%$ & $32,18 \%$ & $67,82 \%$ \\
\hline
\end{tabular}

Figura 3. Postal Tranvía de Iquique

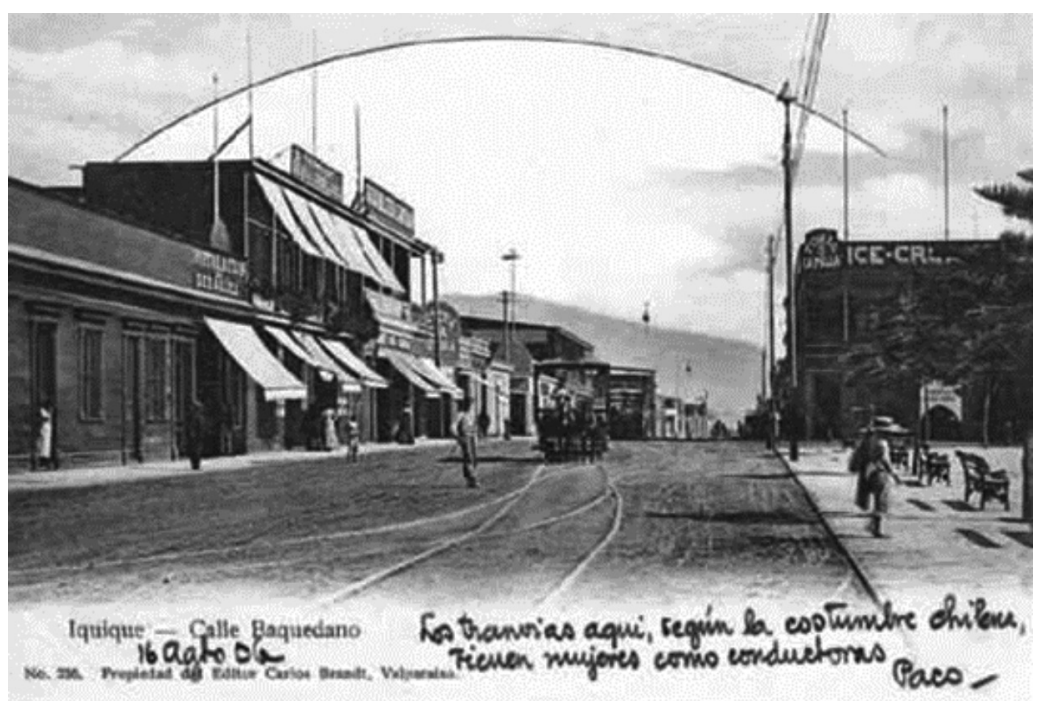

"Los tranvias aquí, según la costumbre chilena, tienen mujeres como conductoras. Paco" (Iquique, 16 agosto 1905. Fotografía gentileza de Juan Vásquez T.)

una nueva forma de organización y gestión de la actividad productiva, sino también como un nuevo ámbito para la inversión de capitales, caracterizado a la vez por el uso de nuevas tecnologías y por la incorporación de una mano de obra adscrita en forma regular" (Escobar 2013).

De esta forma se entiende que la modernización abarca a todas las áreas de la economía y también a las relaciones de producción que se establecieron en esta etapa de desarrollo. Para el caso de la evolución del empleo femenino fabril, Veneros y Ortega señalan que Santiago y Valparaíso concentraron el 58,9\% del total nacional, esta alta concentración se explica por la orientación productiva de las distintas provincias, por tanto Tarapacá, al estar primordialmente orientada a la exportación del salitre y contar con una menor estructura productiva de manufacturas, contó con menores índices de trabajo femenino fabril, lo que 
contribuyó a mantener formas de empleo femenino tradicionales (Veneros y Ortega, 2011). De este modo, si bien en Iquique el trabajo fabril fue una de las áreas con mayor participación de mujeres, debe comprenderse que el ejercicio de dichos oficios no se realizó necesariamente en grandes y modernas fábricas con un elevado número de operarias y altos estándares de mecanización.

Según la información disponible en los Anuarios Estadísticos, puede establecerse que la cantidad de establecimientos fabriles fue escasa en relación con otras ciudades y, por tanto, la disponibilidad de empleos difícilmente podía absorber a la totalidad de las mujeres que declaraban dichos oficios, a partir de ello puede inferirse que gran cantidad de estas trabajadoras se desempeñaban en labores informales o independientes tanto en sus hogares como a domicilio de clientes, ejemplo de ello es el contraste entre los datos aportados por el Anuario Estadístico de 1911 que informa la existencia de 49 establecimientos textiles y de vestuario con 156 operarias $^{3}$ (promedio de 3,1 operarias por establecimiento) frente a los datos del censo de 1907 en donde 2.593 mujeres declararon poseer un oficio en este rubro, es decir que la diferencia entre ambos registros es de 2.437 obreras textiles y de vestuarios, de estas no se tiene claridad respecto de sus fuentes de empleo. Lo mismo sucede con las lavanderas: según el censo de 1907 habían en la región 3.068 lavanderas, no obstante el Anuario Estadístico de 1909 registra 25 establecimientos de lavandería y 131 lavanderas que pagaban patente municipal para ejercer su oficio de forma independiente, es decir que cada establecimiento debiese haber contratado a más de 122 operarias para absorber a toda esa mano de obra disponible, lo que resulta improbable considerando que, en general, los distintos talleres y fábricas de la provincia funcionaban aproximadamente con 3 a 80 operarias y operarios.

A partir de este vacío documental e incertidumbre estadística, es posible aproximar como primera hipótesis que la tasa de empleo al margen de los talleres y fábricas -ya en el propio domicilio, en domicilios particulares o en espacios comunespuede haber sido considerablemente elevada y, por tanto, constituir la forma de empleo más extendida entre las mujeres de la provincia, quedando fuera de los registros oficiales; en esta dirección, Lorena Godoy explica que para el caso de las manufacturas textiles, la base tradicional del trabajo femenino en el propio domicilio prevaleció desde el siglo XIX hasta las primeras décadas del siglo XX y no fue desplazado por el desarrollo de la industria moderna, sino más bien fue utilizado por esta mediante la modalidad de trabajo "a trato" de gran cantidad de obreras que trabajaban desde sus hogares al servicio de fábricas de ropa, lencería, entre otras (Godoy 1995). Esta tendencia puede apreciarse también en otros países latinoamericanos en procesos de temprana industrialización, ejemplo de ello fue el caso de São Paulo en donde, según indican Eni de Mesquita Samara y María Izilda Santos, las mujeres habrían optado por el empleo informal que pudieran realizar en sus propios hogares y, especialmente, en el trabajo a trato en la fabricación de bolsas para la industria cafetera (Samara y Santos, 2006).

El trabajo femenino en este contexto estuvo altamente desregulado y precarizado, el ejercicio informal, esporádico e inestable de los oficios, parece ser el telón de fondo del proceso de inserción laboral de las mujeres a nivel nacional y puntualmente en Iquique. Si bien la realidad de la clase trabajadora en conjunto se caracterizó por las duras condiciones laborales y la inexistencia de una legislación moderna que garantizara derechos básicos, las contradicciones sociales del modelo económico tiendieron a agudizarse si se considera el factor de género como un mecanismo de poder que coadyuvó a aumentar las ganancias del empresariado, mediante la precarización del trabajo femenino al situarlo como una actividad secundaria o complementaria. Para profundizar en las relaciones de poder que se establecen desde la división sexual del trabajo y las relaciones de género, es necesario analizar las características e implicancias de la inserción laboral femenina más allá de las cifras, abarcando su dimensión social, prácticas, discursos, conflictos $\mathrm{y}$ resistencias.

\section{Trabajadoras iquiqueñas: las proletarias del proletariado}

Según Gálvez y Bravo, las mujeres que declararon poseer oficios afirmaban que "los ejercían para sobrevivir" (Gálvez y Bravo, 1992), agregan que sería un mito indicar que la vida moderna incorporó a las mujeres al mercado laboral en un sentido positivo de brindar oportunidades, sino más bien su inserción se trató de una necesidad imperiosa frente a la realidad material de los sectores populares: sus bajos ingresos y los altos costos de la subsistencia (Gálvez y Bravo, 1992). 
Según un estudio de la Oficina del Trabajo de 1913, basado en una muestra de 13 familias iquiqueñas de sectores populares y medios, el promedio de los ingresos eran inferiores a los gastos mensuales (Rodríguez 1913). A lo anterior se agregaba la falta de fiscalización al mercado de consumos que permitía el alza injustificada de precios por parte de los comerciantes, así lo manifistó el periódico El Trabajo en 1906:

\begin{abstract}
"Pedimos al Gobierno que busque la manera de aplicar un castigo dictando una ley para aquellos comerciantes que abusen de las calamidades públicas para hacer su negocio bárbaramente sabiendo el precio de los artículos de consumo. No tiene calificativo la conducta avarienta del comercio al por mayor de este puerto en las actuales circunstancias, que no hay motivo el que menor para justificar el alza de los consumos" (El Trabajo, 1906).
\end{abstract}

El déficit presupuestario de la clase trabajadora fue asociado también con el alto consumo de alcohol y otros vicios, como los juegos de azar y la prostitución. El informe señala que en 6 de las 13 familias encuestadas, existía consumo frecuente de alcohol por parte de uno o ambos cónyuges, mismas familias que contaban con mayor déficit mensual. Sin embargo, independientemente del problema del alto consumo de alcohol entre los sectores populares, el desequilibro entre los salarios y el costo de la vida respondía a causas económicas estructurales. Según Marcello Carmagnani, entre 1895 y 1910 los salarios nominales presentaron continuamente tendencias al alza, sin embargo sugiere que ello no se produjo al mismo ritmo de la inflación, generándose así un desfase entre el aumento del costo de la vida que se tradujo en el alza general de precios entre $5 \%$ y $8 \%$ anual respecto de los salarios percibidos (Carmagnani, 1998); en consonancia con estas estadísticas, los organizadores obreros denunciaban en 1912 la insuficiencia de los salarios:

"Cuando nosotros decimos que la situación económica del pueblo productor es mala, que los salarios son insuficientes y que no alcanzan para el sostenimiento de la familia obrera, no falta quien niege estas verdades y hasta quien asegure que podrían vivir como príncipes si no fuera por los vicios y la idiosincrasia peculiar de nuestro pueblo. No hemos de negar que el pueblo está educado en un ambiente viciado y corrompido y por esta causa ha contraído estos mismos vicios y corrupciones; pero de esto á que los salarios sean suficientes para la vida honesta de los productores hay alguna diferencia" (El Despertar de los Trabajadores, 1912).

Por otra parte, se agrega que este desajuste es uno de los factores que incidían en la urgencia de aumentar el ingreso familiar mediante el trabajo de mujeres y niños, quienes se vieron en la necesidad de buscar estrategias de supervivencia y ocuparse en labores mal remuneradas y bajo condiciones de explotación:

"Estos déficis tienen que cubririse con el trabajo de la mujer mientras abandona el hogar y la familia; con el trabajo prematuro de los hijos sacados de las escuelas para meterles en las fábricas ó en las minas", este déficit se cubre muchas veces, doloroso es decirlo, con la virjinidad de las hijas" (El Despertar de los Trabajadores, 1912).

Las posibilidades laborales de la clase trabajadora hacia finales del siglo XIX e inicios del XX, se ampliaron en la medida en que se diversificaba la economía chilena, no obstante ello no significó un mejoramiento de sus condiciones de existencia ni de su participación en el progreso social, sino que redundaron en experiencias de explotación y empobrecimiento por cuanto constituían la fuerza de trabajo necesaria para la acumulación de capital en manos del empresariado. En el caso específico de la inserción laboral de las mujeres, estaba implícita la posibilidad para el sector empresarial de contar con una fuerza laboral todavía más barata que la ya precarizada mano de obra masculina, ello en razón de los roles de género relacionados con la división sexual del trabajo, a partir de ello las mujeres no son en sí mismas sujetos trabajadores -sobre ello se volverá más adelante-. Por tanto, el mercado laboral no se abrió para proveerlas de mejoras a sus condiciones de vida ni estuvo pensado para desarrollar sus capacidades y elevar su estatus en la sociedad, sino que se presentó como una oportunidad para los sectores empresariales de disponer de una amplia masa de mano de obra barata 
que permitiría disminuir costos de producción y, consiguientemente, aumentar sus ganancias, a este respecto señala Joan Scott

"Dónde trabajaban las mujeres y qué hacían no fue resultado de ciertos procesos industriales ineluctables, sino, al menos en parte, de cálculos relativos al coste de la fuerza de trabajo. Ya sea en la rama textil, en la fabricación de calzado, en la sastrería o el estampado, ya sea en combinación con la mecanización, la dispersión de la producción o la racionalización de los procesos de trabajo, la introducción de las mujeres significaba que los empleadores habían decidido ahorrar costes de fuerza de trabajo" (Scott, 2006).

Por otra parte, su incorporación a los rubros anteriormente analizados se produjo bajo condiciones desfavorables y precarias que generaron controversias en todos los sectores sociales, constituyendo el trabajo femenino uno de los grandes problemas dentro de los debates en torno a la cuestión social. Las extensas jornadas, accidentes y enfermedades laborales, la inestabilidad y la poca regulación por parte del Estado, los bajos salarios, entre otras, son algunas de las problemáticas que las obreras experimentaron tanto a nivel nacional como en la región de Tarapacá.

Las áreas en que se intensificó la concentración de mano de obra femenina se caracterizaron por desarrollarse en ambientes de infraestructura precaria, higiene deficiente, hacinamiento, humedad y poca ventilación, lo que aparejó como consecuencia impactos en la salud de las trabajadoras. A nivel nacional, las denuncias respecto de las condiciones de salubridad de los talleres y fábricas manufactureras en que operaban mujeres y niños fueron constantes, en el informe presentado por Manuel Rodríguez Pérez respecto de las condiciones laborales en Iquique en 1913, se detalla que

"En efecto, el mal estado de los talleres, la falta absoluta de higiene y de las más esenciales condiciones para hacer cómoda y saludable la permanencia en los sitios de trabajo, es la norma general en las fábricas y talleres de Iquique. Todos los talleres, todas las fábricas, son grandes galpones con piso de tierra, donde el aseo solo se conoce de nombre y donde, por tanto, los obreros están expuestos a ser víctimas de toda clase de enfermedades" (Rodríguez, 1913: 48).

Estas condiciones propiciaban enfermedades como la tuberculosis, la que constituyó una de las principales causas de muerte entre los habitantes de la provincia de Tarapacá en este periodo; además de ello, se propagaban diversas enfermedades pulmonares crónicas y afecciones a la piel causadas por el polvo en suspensión y por las cualidades propias de los materiales empleados en la producción (por ejemplo, químicos, residuos metálicos, fibras textiles, entre otros). Las obreras textiles, sin duda las más numerosas dentro del ámbito manufacturero, se vieron expuestas al deterioro de las articulaciones de las manos por la minuciosidad que requerían sus labores, daños a la vista por la poca iluminación de los talleres, además de problemas en la columna por la gran cantidad de horas que permanecían sentadas. Según apuntan De Mesquita y Santos para el caso de la ciudad de São Paulo, estas malas condiciones también fueron padecidas por las trabajadoras que operaban en sus domicilios llegando a sufrir enfermedades crónicas producto de sus labores (Samara y Santos, 2006). Considerando la insalubridad de los conventillos en la ciudad de Iquique, es presumible que la realidad local no distara del relato de las citadas autoras, de ello da cuenta la prensa obrera local al retratar la imagen cotidiana de una costurera que, poco a poco, fue constituyéndose en un emblema de las luchas populares.

\section{"Una joven obrera, de esas que a centenares existen en las grandes capitales, bellas y desgraciadas hijas del amor y de la miseria, está sentada en su indijente taller de costura. La cara de la joven es pálida, tiene la palidez de los lirios enfermos porque la terrible enemiga, la tisis, ha puesto sobre su faz el sello triste" (El Pueblo Obrero, 1906).}

En cuanto a la lavandería, las problemáticas higiénicas estaban vinculadas con la humedad y el contacto con aguas insalubres, ya que para este periodo el sistema de alcantarillado en Iquique era prácticamene inexistente. Según Carlos Donoso, la segregación espacial hacia la periferia de la ciudad de Iquique determinó que gran parte de la población no se beneficiara de las incipientes obras públicas 
de alcantarillado que datan de 1893, mientras que el retiro de aguas servidas continuó haciéndose mediante medios arcaicos hasta la década de 1920 (Donoso, 2018). De esta forma, aquellas mujeres que ejercían este oficio en sus hogares, principalmente ubicados al interior de conventillos, estuvieron en contacto cotidianamente con aguas estancadas y en un entorno húmedo, en donde la formación de barro acarreaba otros problemas como malos olores, mosquitos e infecciones. Alba David comenta la situación de las lavanderas de Medellín en su temprana industrialización de la siguiente forma:

\begin{abstract}
"Este debió ser uno de los oficios más duros porque implicaba pasar varias horas inclinadas sobre grandes y lisas piedras encogidas en las orillas [del río], a la interperie, con el agua en los pies o a media pierna. [...] En estas circunstancias es fácil deducir que las lavanderas debieron padecer constantes problemas de salud producto de su contacto con aguas sucias y contaminadas, haciendo más dura su labor" (David, 2007).
\end{abstract}

Pese a las diferencias entre las ciudades de Iquique y Pisagua respecto de Medellín, principalmente en relación con el lavado en río, consideramos que los perjuicios para la salud de las mujeres producto de las condiciones en que trabajaban fueron similares, incluso para quienes se emplearon en talleres de lavado, pues, de igual forma, convivían con la humedad y variaciones de temperatura que incidían en el contagio de gripes y enfermedades pulmonares, con los químicos utilizados en el proceso de lavado y con las largas horas de pie. Frente a las desfavorables condiciones de trabajo de las lavanderas, el Partido Demócrata proponía como séptimo punto del programa presentado en su campaña para las elecciones municipales de 1912 en Iquique la mecanización de esta actividad, señalando que "El Partido Demócrata establecerá lavanderías y aplanchadurías municipales, para extirpar la explotación de que son víctimas las obreras de este ramo y para poner á un precio bajo la limpieza de la ropa, que es belleza y que es placer" (El Despertar de los Trabajadores, 1912).

Basados en los ingresos de los hospitales de Iquique y Pisagua, registrados en el Anuario Estadístico de 1910, podemos aproximar las principales tendencias en materia de enfermedades que afectaban a la población femenina en el periodo.
Dicho año, la mayor cantidad de atenciones a mujeres en los hospitales de ambos puertos correspondían a tuberculosis, influenza, afecciones estomacales (diarreas, enteritis), enfermedades venéreas y septicemia puerperial (entre otras enfermedades relacionadas con el parto), estas enfermedades concentraron el $43,7 \%$ del total de las atenciones anuales, la mayor parte de estas afecciones -salvo las dos últimas- estaban relacionadas con los problemas de higiene reseñados anteriormente. Por otra parte, en relación con las profesiones de las ingresadas, se indica que el $38,5 \%$ no poseían profesión, 19,5\% eran lavanderas, $12 \%$ modistas y $11,4 \%$ se registró con oficios varios, estas cifras muestran una coincidencia entre las principales ocupaciones de las mujeres ingresadas a los hospitales y el tipo de enfermedades que mayormente las aquejaban, según se analizó anteriormente. De modo similar, según la Oficina del Trabajo en su boletín de 1912, el primer semestre de dicho año las mujeres ingresadas al Hospital de Iquique principalmente eran "jente casera" (469), seguidas por lavanderas y aplanchadoras (220), costureras y sastres (140) y sirvientes y cocineras (130).

El servicio doméstico estuvo altamente feminizado, por cuanto las labores que comprende componían precisamente el espectro de tareas que desde la infancia son aprendidas por las mujeres como "deberes inherentes a su sexo", sin mayor especialización que los saberes transmitidos y socializados por otras mujeres. De esta forma, las mujeres de sectores populares se volcaron a un mercado laboral de cuidados y servicios que demandaba por cocineras, empleadas para la limpieza, nodrizas, etc. Generalmente, bajo la rúbrica de "sirvienta" se mezclaban más de una labor, haciéndose cargo de todo lo que se necesitara para asegurar el bienestar cotidiano de la familia empleadora.

En el servicio doméstico se produjo una pervivencia de relaciones de tipo serviles hasta mediados del siglo XIX, siguiendo a Sergio Grez, a partir de las transformaciones políticas, culturales y económicas imbricadas en la transición capitalista en Chile, dichas relaciones se modernizaron -en términos de monetarizar el salario y regular las formas contractuales- socavando las antiguas formas de sumisión y disciplina que se ejercían en quienes se ocupaban en estos oficios, de esta forma la élite chilena debió recurrir a nuevos mecanismos coercitivos dentro de relaciones laborales de tipo capitalistas, para ello buscó reglamentar el trabajo 
doméstico mediante instrumentos legales como el Código Civil de 1855, en donde se establecen disposiciones rigurosas orientadas a reactualizar la dominación acerca de la servidumbre (Grez, 2007).

Grez comenta al respecto que se establecieron disposiciones respecto de la duración y término de los contratos laborales que perjudicaban a las y los sirvientes ya que debían indemnizar a sus patrones en caso de causarles perjuicios al renunciar, lo que se acentuaba en el caso de las nodrizas, ya que se consideraba que poner fin a su contrato repercutiría en la salud del lactante, además de ello se estipulaba respecto del pago de los salarios que en dicha materia la palabra del empleador sería considerada como verídica -especialmente en torno a deudas, pagos, adelantos, etc.--, dejando abierta la puerta a múltiples abusos, un caso particular fue expuesto por el periódico El Tarapacá en Iquique en 1894 comentando un supuesto robo cometido por una sirvienta, quien previamente había dado aviso a su patrona acerca de su voluntad de poner fin a su relación laboral.

“Trinidad Rodríguez, muchacha que servía en una casa respetable, manifestó a la patrona que no quería seguir sirviendo. Pero la dueña de casa, con razón ó sin ella, acusó acto contínuo á la Trinidad de haberle robado: 2 enaguas, 2 camisas de dormir, 4 cucharas grandes de plata, 1 pulsera de oro, 1 par de sábanas, 2 guardapelo y 3 pañuelos de seda. La Trinidad dice que no es cierto que haya robado tales especies, pero la señora afirma en lo dicho" ( $E l$ Tarapacá, 1894).

Los malos tratos hacia las trabajadoras se produjeron en todas las áreas de trabajo. El Despertar de los Trabajadores denunciaba a fines de 1912 los abusos que padecían las operarias de la lavandería del ejército, quienes además de percibir bajos salarios debían soportar las malas prácticas del administrador como prestar servicio en su domicilio particular y no poder elevar quejas a las autoridades militares bajo amenazas de despido.

"A todo esto hay que añadir que estas operarias reciben un trato brutal de dicho administrador, que se complace en llamar "chinas ladronas" á las que tienen que ganarse allí su vida. A esta jente que vive de su salario ganado duramente en aquel establecimiento, se les mantiene, en ocasiones, hasta dos meses sin el pago de sus sueldos y cuando después de muchos trajines, consiguen que haya pago, les ofrecen el sueldo de 15 ó 20 días y si se quejan porque no se les abona todo, las mandan cambiar sin nada" (El Despertar de los Trabajadores, 1912).

Pocos días después de publicadas estas denuncias, el administrador del establecimiento se habría acercado hasta la imprenta del periódico para desmentir las acusaciones, señalando entre sus descargos que ninguna operaria prestaba servicios en su domicilio, sin embargo "se suele lavar ropa de algunos jefes pero que esto no es incumbencia de él evitarlo, ni perjudica á la casa" (El Despertar de los Trabajadores, 1913), lo que sigue constituyendo una irregularidad. Consideramos que este tipo de malos tratos se producían por la nula fiscalización y la ausencia de una legislación que protegiera la integridad de las trabajadoras, por otra parte la obediencia y sumisión de las mujeres como parte del constructo cultural de la feminidad conllevó constantemente a ejercer este y otro tipo de abusos bajo la creencia de que las mujeres tolerarían cualquier situación similar, por cuanto constituían una mano de obra dócil, sumisa y disciplinada. No obstante, la respuesta de las operarias de la lavandería del Ejército se tradujo en la primera huelga de obreras documentada en Iquique 4 .

Otro aspecto que marcó el trabajo femenino en este contexto fue la extensión horaria de la jornada laboral, según consigna el informe de Manuel Rodríguez Pérez, en Iquique

"La estadía en las fábricas, que fluctúa entre 9 y 12 horas, es igual para los hombres, las mujeres y los niños, sin que ninguna disposición legal, administrativa o municipal ordene a los patrones limitar la jornada del trabajo a las mujeres en pleno período de embarazo o a los niños menores de 15 años" (Rodríguez, 1913).

Esta problemática se suscitó en cada uno de los rubros en que se empleó la mano de obra femenina, destacando que el trabajo en el domicilio y "a trato" no se escapaban de esta situación, por cuanto el salario dependía de la cantidad de productos que 
lograban elaborarse, de forma que quienes ejercían su oficio bajo esta modalidad destinaban hasta 14-16 horas diarias al trabajo. Es importante señalar, por lo demás, que bajo esta modalidad de trabajo los empleadores abarataban costos asociados como el financiamiento de salas cunas en instalaciones de más de 50 operarias -cifra establecida por la ley de Salas Cunas de 1917- y el pago por los productos elaborados quedaba al arbitrio del patrón si consideraba que alguno resultaba defectuoso o incompleto. Tanto la regulación de la jornada de trabajo femenino como el trabajo "a trato" constituyeron una preocupación para los organizadores obreros, reflejo de aquello es que en el primer programa del Partido Obrero Socialista publicado tras su fundación en 1912 se expresa la necesidad de "Supresión de todo trabajo á trato ó pieza. Supresión del trabajo de la mujer durante la noche ó en los meses de embarazo y del niño analfabeto" (El Despertar de los Trabajadores, 1912).
Hacia inicios del siglo XX, uno de los grandes conflictos que enfrentó a los trabajadores con el empresariado, desatando importantes movimientos huelguísticos, fue la problemática salarial. A grandes rasgos puede señalarse que los salarios percibidos lograban cubrir -en el mejor de los casos- las necesidades básicas de la familia obrera, sin existir mayor regulación por parte del Estado en torno a esta temática, esta realidad se extendía a todos los sectores productivos siendo el sector fabril uno de los que pagaba salarios un tanto más altos. En el caso de la mano de obra femenina, esta situación se agudizó por factores de índole tanto económica como sociocultural que determinaron diferencias salariales sustanciales entre trabajadoras y trabajadores, aun en la realización de las mismas tareas y por similares jornadas laborales. La brecha salarial, que caracterizó al empleo femenino, estuvo en directa relación con que su inserción se produjo en actividades poco valoradas, que no requerían de

Figura 4. Promedio de salarios en el sector fabril en Iquique 1912.

\begin{tabular}{|c|c|c|c|c|c|c|}
\hline \multirow{2}{*}{ Gremios } & & \multicolumn{3}{|c|}{ Salarios } & \multirow{2}{*}{$\begin{array}{l}\text { Por hora, } \\
\text { día o mes }\end{array}$} & \multirow{2}{*}{$\begin{array}{c}\text { Horas de } \\
\text { trabajo }\end{array}$} \\
\hline & & Máximo & Medio & Mínimo & & \\
\hline \multirow[b]{2}{*}{ Taller de costuras } & Costureras & 2,00 & 1,50 & 1,00 & Día & 9 \\
\hline & Aprendices & - & 0,50 & - & Día & - \\
\hline \multirow{5}{*}{$\begin{array}{l}\text { Fábrica de chocolate, } \\
\text { hielo y dulces }\end{array}$} & Mecánicos & 15,00 & - & 13,33 & Día & 12 \\
\hline & Peones & 5,00 & - & 4,00 & Día & 10 \\
\hline & Maestros dulceros & 9,00 & - & 6,00 & Día & 10 \\
\hline & Ayudantes dulceros & 4,00 & - & 2,00 & Día & 10 \\
\hline & Empaquetadores & 2,00 & - & 1,00 & Día & 10 \\
\hline \multirow{4}{*}{ Fábrica de calzado } & Zapateros & 9,00 & 5,94 & 1,20 & Día & 9 \\
\hline & Preparadoras & - & 4,00 & - & Día & 9 \\
\hline & Auxiliares hombres & 6,00 & - & 5,00 & Día & 9 \\
\hline & Auxiliares niños & 4,00 & - & 2,00 & Día & 9 \\
\hline \multirow{9}{*}{$\begin{array}{l}\text { Talleres } \\
\text { de lavandería }\end{array}$} & Aplanchadoras & 3,25 & 2,81 & 2,00 & Día & 11 \\
\hline & Lavanderas & 2,00 & 1,87 & 1,50 & Día & 11 \\
\hline & Camiseras & - & 3,00 & - & Día & 11 \\
\hline & Pasa cuellos y puños & - & 3,00 & - & Día & 11 \\
\hline & Ropa fina y sombreros & - & 2,50 & - & Día & 11 \\
\hline & Ternos & - & 4,00 & - & Día & 11 \\
\hline & Ropa lisa & - & 1,50 & - & Día & 11 \\
\hline & Mecánicos & 2,50 & 2,15 & 1,80 & Día & 11 \\
\hline & Maquinistas & - & 4,00 & - & Día & 11 \\
\hline \multirow[b]{2}{*}{ Sastrerías } & Cortadores & 500,00 & 350,00 & 200,00 & Mes & - \\
\hline & Operarios & 7,00 & 4,25 & 2,00 & Día & 10 \\
\hline \multirow{3}{*}{ Panaderías } & Panaderos & 15,00 & 7,19 & 6,00 & Día & 8 \\
\hline & Repartidores & 15,00 & 7,00 & 5,00 & Día & 8 \\
\hline & Vendedores & 6,00 & - & 4,00 & Día & 10 \\
\hline
\end{tabular}

Fuente: Rodríguez, Manuel. El Trabajo y la vida obrera en Tarapacá, 1913. 
mayor calificación y, por tanto, obtenían menores remuneraciones.

Según los datos expuestos, los oficios que concentraron la mayor cantidad de trabajadoras mujeres, como la costura y la lavandería, contaban con salarios más bajos que otras ocupaciones, considerando incluso que las lavanderas tenían, según este informe, jornadas laborales más extensas $\mathrm{y}$, por otra parte, que la costura involucra cierto grado de conocimientos técnicos mayores que los de un vendedor o un peón, quienes sin embargo obtenían mayores remuneraciones promedio. Para el caso de las panaderías y fábricas de chocolates, hielo y dulces, podemos señalar que las mujeres se concentraron comúnmente en las actividades peor remuneradas, como vendedoras y empaquetadoras. En las fábricas de zapatos las mujeres se ocuparon como aparadoras, cuyo salario promedio también resultó inferior en relación con el de los zapateros, cuyo oficio implicaba mayor calificación. Como se puede observar, los salarios femeninos difícilmente alcanzaban para costear holgadamente la vida de un núcleo familiar, por tanto la pobreza urbana adquiría un semblante aún más amargo entre las mujeres, especialmente aquellas que eran el único sustento de sí mismas y sus familias, un cuadro de esta problemática aparece reseñado en El Desperar de los Trabajadores producto del suicidio de una lavandera en 1913:

"La prensa local se ha ocupado del suicidio de María Raspillosa, mujer pobre y con dos hijos: una niña y un niño. Aunque esta mujer trabajaba como lavandera, según los datos publicados, el miserable salario no le alcanzaba, y al no ver ante sí mas porvenir que el de la esclavitud y la opresión prefiere la muerte entregándose con sus hijos en brasos al mar" (El Despertar de los Trabajadores, 1913).

En esa misma dirección, se denunciaba en la prensa contemporánea que los bajos salarios femeninos propiciaban el peligro de la prostitución, obligando a las obreras complementar por esta vía los exiguos salarios que percibían.

Uno de los factores que incidió en el fenómeno de las brechas salariales fue de carácter económico y dice relación con la posibilidad aprovechada por el empresariado industrial de abaratar costos mediante la contratación de mujeres, ya que el pago de menores salarios se justificaba en la baja tasa de especialización de la población femenina en oficios fabriles, teniendo en cuenta, por lo demás, que la educación no estuvo orientada a capacitar a las mujeres en oficios sino hasta la creación de las Escuelas Profesionales de Niñas a partir de 1888 (Godoy, 1995). Dicha mano de obra podía entonces destinarse a labores consideradas de menor rango y que no requerían de gran calificación, según Hutchison, el efecto que de ello se derivó fue la brecha salarial entre hombres y mujeres en el trabajo manufacturero, pagándose a estas últimas aproximadamente la mitad de lo que se pagaba a los varones a nivel nacional, pero ello también se habría extendido a las actividades comerciales y de servicios (Hutchison, 2006), lo que nos indica que no solo tiene que ver con el nivel de calificación y su respectiva justificación económica -porque el servicio doméstico y el comercio carecían de complejidad tecnológica y de mecanización- sino también con la existencia de elementos culturales asociados a la estructura de la división sexual del trabajo que pugnaban en medio de las transformaciones productivas que vivía el país.

Respecto de lo anterior, señala Luz Gabriela Arango que

"La consideración de que las mujeres y los niños carecen de saberes industriales se deriva, por una parte, de su comparación con el saber del obrero profesional como cuerpo formalizado de conocimientos, codificados y transmitidos entre trabajadores a través de las antiguas corporaciones, y por otra parte, remite a una jerarquía de trabajos y saberes que coloca en un segundo plano aquellos que provienen del ámbito doméstico, regidos por pautas de transmisión no formalizadas ni reconocidas" (Arango, 1994).

Siguiendo a Arango, no fueron solo las habilidades manuales adquiridas por las mujeres desde la infancia lo que resultó clave en su inserción en el trabajo industrial, sino que también valores característicos inculcados tanto en los hogares como en las escuelas relacionados con la "constancia, disciplina, minucionsidad, paciencia, obediencia..." (Arango, 1994). Las mujeres se configuraron de esta forma como un actor subordinado y secundario en el mercado laboral fabril en relación con concepciones en 
torno al género, cultural e históricamente definidas en este contexto a partir de la asociación entre una supuesta naturaleza femenina y las actividades que son propias de su sexo, de esta forma las actividades y conocimientos socializados al interior del hogar permanecieron siendo poco valorados, pese a ejercerse como labores remuneradas orientadas al mercado -productivas- y no solo como parte de los quehaceres domésticos considerados meramente reproductivos.

Esta concepción como mano de obra secundaria se extendió más allá del rubro fabril, según se mencionó anteriormente, también en el comercio y los servicios se puede observar que las mujeres se concentraron en empleos en los que desplegaban aprendizajes adquiridos en la vida doméstica y, por tanto, constituyeron de igual forma empleos poco valorados socialmente, en especial aquellos relacionados con el servicio doméstico. En ese sentido, es admisible destacar que esta noción implicó tanto la concentración de trabajadoras en determinados oficios altamente feminizados como también en determinadas actividades "secundarias" o subordinadas en jerarquías al interior de oficios mixtos. La generalidad fue por tanto la poca valoración social y la consiguiente inferioridad salarial. Así, se construye de forma ideológica una segregación en el mercado laboral a partir del sistema sexo-género. Según explica Carmuca Gómez, las mujeres se ocupan de labores consideradas inferiores no por la fuerza empleada en ellas sino por cuanto consituyen una extensión del mundo doméstico, Gómez agrega además que esta construcción de espacios y características ocupacionales diferenciadas por sexo contribuyen a reforzar las estructuras que las definen (Gómez, 2001). Se puede sostener que la segregación laboral operó por una parte como un mecanismo para justificar la inferioridad salarial,y por otra, para validar la estructura social basada en la división sexual del trabajo tradicional, en donde se define el trabajo productivo como una actividad masculina y las labores reproductivas como femeninas, se refuerzan además los mandatos jerárquicos de género que parecían estremecerse ante el ingreso de las mujeres al trabajo remunerado -o su visibilización- fuera del hogar, acentuando la figura y autoridad del varón como trabajador y proveedor.

Otro aspecto que contribuyó a mantener bajos los salarios de las mujeres fue el hecho de considerarlos como ingresos complementarios para la familia obrera. La idea de que las mujeres comenzaran a dejar sus hogares para emplearse en las distintas posibilidades que les presentaba el mercado laboral hacia principios del siglo XX como una forma de ayudar al esposo o padre, responde al hecho de que el sueldo promedio de los trabajadores era insuficiente para cubrir los gastos de una familia, al respecto $E l$ Despertar de los Trabajadores argumentaba que

"Por último, no es el movimiento femenino el que substrae a la mujer de las funciones del hogar para lanzarla cada vez mas en el turbio y vertiginoso torbellino de la lucha por la vida, no; es la miseria. La insuficiencia del salario del hombre que muy comunmente no basta a subvenir a todas las necesidades de la familia, es lo que obliga a la mujer á abandonar las funciones del hogar para arrojarse al campo de la producción y del trabajo" (El Despertar de los Trabajadores, 2013).

Del mismo modo se pensaba como una posibilidad en casos de extrema necesidad ante situaciones como el alcoholismo, la cesantía o la defunción del jefe de hogar, lo que supone un sentido de transitoriedad y causalidad al rol de las mujeres en tanto trabajadoras.

Para Joan Scott, este supuesto respecto del salario de las mujeres se basa en las teorías de la economía política del siglo XIX que sustentaban la clásica división sexual del trabajo; según esto, el salario del obrero debía ser suficiente para sustentar a su núcleo familiar, siendo las mujeres sujetos dependientes por naturaleza que no necesitaban autosustentarse, así

"En esta teoría, el salario del trabajador tenía un doble sentido. Por un lado, le compensaba la prestación de su fuerza de trabajo y, al mismo tiempo, le otorgaba el estatus de creador de valor en la familia. Puesto que la medida del valor era el dinero, y puesto que el salario del padre incluía la subsistencia de la familia, este salario era el único que importaba. Ni la actividad doméstica, ni el trabajo remunerado de la madre era visible ni significativo. [...] Cuando ellas o sus familias necesitaban dinero, las mujeres salían a ganarlo. [...] No importaba cuáles fuesen sus circunstancias 
-que se tratara de solteras, casadas, cabezas de familia o único sostén de padres o hermanos dependientes-, sus salarios se fijaban como si fueran suplementos de los ingresos de otros miembros de una familia" (Scott, 2006).

\section{Conclusiones}

Como se ha analizado, la inserción de las mujeres al trabajo remunerado extradoméstico estuvo supeditada tanto a los requerimientos del mercado laboral como a cuestiones de índole ideológica en torno al género consideradas en este periodo como leyes naturales, destinando a las mujeres a tareas poco valoradas y mal remuneradas que remarcaban sus roles tradicionales, su calidad de reproductoras y el ámbito doméstico como su espacio natural de desenvolvimiento, mientras que el trabajo se consolidaba como una labor destinada a los hombres.

La variable de género atravesó de manera transversal las características del proceso de inserción laboral femenina en Tarapacá, especialmente en aquellos rubros que se expandieron con el desarrollo urbano, configurando identidades masculinas y femeninas a partir de las relaciones de producción. El proceso de proletarización implicó reordenar las relaciones de género para fortalecer las jerarquías sociales tradicionales inscritas en el proyecto societal emanado de las élites gobertantes, en concordancia con los requerimientos de la economía nacional; para ello fue necesario implementar distintos mecanismos de control social que permitiesen disciplinar la mano de obra, en ese sentido las relaciones laborales que se establecieron en este periodo se encaminaron a dicho objetivo de forma diferenciada para hombres y mujeres, constituyéndose así al hombre como el sujeto trabajador/proveedor por excelencia, mientras que las mujeres desde su posición subordinada se ocuparon de actividades de poca valoración social y productiva, constituyéndose en mano de obra barata y secundaria, reforzando así su función materna y sus roles domésticos tradicionales, como eje articulador de la familia obrera. De esta forma, se establece que las características de la inserción laboral de las mujeres en Tarapacá coadyuvaron a la reactualización y reproducción de relaciones jerárquicas de género.

Al hacer referencia a la inserción laboral femenina, se nos figura un proceso acelerado y masivo de incorporación de mujeres a grandes fábricas e industrias con altos estándares de mecanización, sin embargo las cifras que presentan los censos y Anuarios Estadísticos en relación con la realidad de la industrialización en las zonas urbanas de Tarapacá no encajan con esta imagen, por ejemplo, el hecho de que hubiesen aproximadamente cuatro mil obreras textiles no es sinónimo de que todas estuviesen empleadas en fábricas modernas, ya que el desarrollo manufacturero en las áreas en que se insertaron las mujeres en la región no tuvieron la capacidad ni la infraestructura para absorber a la totalidad de la mano de obra disponible, es decir que el desarrollo productivo de las industrias manufactureras no se produjo al mismo ritmo que en otras ciudades como Valparaíso o Santiago. Asimismo, consideramos que las ideas que se han formado en torno al trabajo femenino responden a la escasez de registros estadísticos y documentales de mayor precisión, esto responde al hecho de que desde el siglo XIX la mano de obra femenina se ha considerado como secundaria, por tanto su empadronamiento no revestía la misma importancia que los varones.

La división sexual del trabajo se reactualizó a base de los desafíos y transformaciones que se presentaron en este contexto, especialmente en relación con las mutaciones en la estructura productiva. Así, las formas tradicionales de concebir los roles de la masculinidad y feminidad previos a la incorporación de Chile al capitalismo mundial debieron ajustarse frente al curso que adquirían las relaciones de producción, por tanto se produjo una tensión entre las identidades de género tradicionales y la pujanza de nuevas formas de ser y comportarse como hombres y mujeres. Similarmente, las estructuras familiares propendidas por la oligarquía debieron readecuarse a los requerimientos de la incipiente industrialización del país, no obstante hubo elementos que se mantuvieron inalterados como la condición subordinada de la mujer y la potestad de los varones.

Por otra parte, sostenemos que la unidad doméstica y, correlativamente, la familia no son los únicos espacios en donde se produce y reproduce la sumisión de las mujeres, sino que el trabajo asalariado y los espacios segregados coadyuvaron a definir dónde, cómo y cuánto pueden trabajar las mujeres, de modo que operaron en dirección de mantener -e incluso reforzar- su condición subordinada y la autoridad masculina. 


\section{Referencias Citadas}

\section{Fuentes}

Anuarios Estadísticos 1909-1918.

ARNIT vol. 384 foja $\mathrm{N}^{\circ}$ 104, junio de 1899.

Boletín de la Oficina del Trabajo, año IV $\mathrm{N}^{\circ}$ 9, segundo semestre de 1914.

Dirección General de Estadística. Séptimo censo general de la población de Chile levantado el 28 de noviembre de 1895, tomo I.

Dirección General de Estadística. Octavo censo general de la población de Chile, levantado el 28 de noviembre de 1907.

Dirección General de Estadística. Noveno censo de población de Chile levantado el 15 de diciembre de 1920.

El Despertar de los Trabajadores, Iquique.

El Pueblo Obrero, Iquique.

El Tarapacá, Iquique.

El Trabajo, Iquique.

Prado, Alberto. Anuario Prado Martínez. Única Guía General de Chile 1904-1905. Centro Editorial de Alberto Prado Martínez. Santiago, Chile, 1905.

\section{Bibliografía}

Arango, L.

1994 "Industria textil y saberes femeninos". Revista Historia Crítica (n ${ }^{\circ}$ 9), 44-49. doi: https://doi.org/10.7440/ histcrit9.1994.06.

Brito, A.

2014 Autonomía y subordinación. Mujeres en Concepción, 1840-1920. Santiago, Chile: LOM Ediciones.

1995 "Del rancho al conventillo: transformaciones en la identidad popular femenina, Santiago de Chile, 1850-1920". En Godoy, L., Hutchison, E., Rosemblatt, K., y Zárate, M. Disciplina y Desacato, construcción de identidad en Chile, siglos XIX y XX (pp. 27-69). Santiago, Chile: Ed. SUR/CEDEM.

Carmagnani, M.

1998 Desarrollo industrial y subdesarrollo económico, el caso chileno (1860-1920). Santiago, Chile: Dirección de Archivos y Museos DIBAM.

David, A.

2007 "Las trabajadoras de Medellín: entre la necesidad y la exclusión (1850-1900)". Revista Historia y Sociedad, ( $\mathrm{N}^{\circ}$ 13), 91-109. Recuperado de http://bibliotecavirtual. clacso.org.ar/ar/libros/colombia/fche/5.pdf

Donoso, C.

2018 Una región rica, fértil y abandonada: economía, cultura y sociedad en Tarapacá (siglos XVI-XX). Arica, Chile: Ediciones Universidad de Tarapacá.

Escobar, D.

2013 "El mercado laboral femenino e infantil en Antofagasta, 1880-1930". Revista Historia, vol. II (No 46), 343-394.

Gálvez, T., Bravo, R.

1992 "Siete décadas de registro del trabajo femenino 18541920”. Revista Estadísticas y Economía (№ 5), 1-52.

Grez, S.

1995 La cuestión social en Chile, ideas y debates precursores (1804-1902). Fuentes para la Historia, de la República vol. VII. Santiago, Chile: Ediciones de la Dirección de Bibliotecas, Archivos y Museos.

Godoy, Lorena

1995 "Armas ansiosas de triunfo: dedal, agujas, tijeras.. La educación profesional femenina en Chile 1888-1912". En Godoy, L., Hutchison, E., Rosemblatt, K. y Zárate, M. (Ed.), Disciplina y Desacato: construcción de identidad en Chile siglos XIX y XX (pp. 71-110). Santiago, Chile: Editorial SUR/CEDEM.

González, S.

2014 "Las inflexiones de inicio y término del ciclo de expansión del salitre (1872-1919). Una crítica al nacionalismo metodológico". Revista Diálogo Andino (№ 45), 39-49.

Gómez, C.

2001 Mujeres y trabajo: principales ejes de análisis. Papers Revista de Sociología, vol. 63, 123-140.

Hutchison, E.

2006 Labores propias de su sexo. Género, políticas y trabajo en Chile urbano 1900-1930. Santiago, Chile: LOM Ediciones.

2000 "La historia detrás de las cifras: la evolución del censo chileno y la representación del trabajo femenino, 18951930". Revista Historia, vol. 33, 417-434. doi: http://dx.doi. org/10.4067/S0717-71942000003300009.

Mauro, A., Godoy, L. y Díaz, X.

2009 Trabajo y empleo femenino en Chile: 1880-2000. Su aporte al desarrollo del país desde la economía doméstica, el trabajo voluntario y el trabajo remunerado (Informe final de Proyecto Fondecyt Regular código 1060057). Centro de Estudios de la Mujer CEM, Santiago, Chile.

Morrison, A.

2008 Los Tranvías en Chile (1858-1978). Santiago, Chile: Editorial Ricaaventura.

Pinto, J.; Ortega, L.

1990 Expansión Minera y Desarrollo Industrial: un caso de crecimiento asociado (Chile 1850-1914). Santiago, Chile: Universidad de Santiago de Chile.

Rodríguez, $\mathrm{M}$.

1913 El Trabajo y la vida obrera en Tarapacá. Oficina del Trabajo. Santiago, Chile: Imprenta Santiago.

Samara, E., Santos, M.

2006 "Manos femeninas. Trabajo y resistencia de las mujeres brasileñas (1890-1920)". En G. Duby, M. Perrot, (Ed.), Historia de las Mujeres en Occidente, vol. 5, El Siglo XX (775-786). Barcelona, España: Editorial Taurus.

Scott, J.

2006 "La mujer trabajadora en el siglo XIX". En G. Duby, M. Perrot (Ed.), Historia de las Mujeres en Occidente vol. 4, El Siglo XIX (pp. 433-434). Barcelona, España: Editorial Taurus.

Tatjer, M.

2002 "El trabajo de la mujer en Barcelona en la primera mitad del siglo xx: lavanderas y planchadoras". Scripta Nova, Revista Electrónica de Geografía y Ciencias Sociales, vol. VI (No 119). Recuperado de http://www.ub.es/geocrit/ $\mathrm{sn} / \mathrm{sn} 119-23 . \mathrm{htm}$

Veneros, D., Ortega, L.

2011 "Trabajo femenino en un contexto de modernización: una visión de su evolución por provincias, Chile, 19101930”. Revista Universum, vol. 1 (№ 26), 151-168. 


\section{Notas}

1 Cálculos realizados a base de la información extraída de Censos de Población de 1895, 1907 y 1920, disponibles en http://www.ine.cl.

2 Cifras extraídas de Censos de Población 1895, 1907 y 1920.

3 Anuario Estadístico de 1911. Dirección General de Estadísticas, Santiago, Chile.

4 Según consigna la prensa, cuatro operarias paralizaron sus labores en protesta por los malos tratos recibidos, siendo posteriormente despedidas, lo que motivó que otras operarias se sumaran a la huelga exigiendo la reincorporación de sus compañeras de labores. No descartamos la posibilidad de que hechos similares hayan ocurrido con anterioridad en la provincia, no obstante no hemos encontrado documentos que así lo acrediten. Esta noticia puede encontrarse en $E l$ Despertar de los Trabajadores No 173 año I, 4 de enero de 1913. 